\title{
RASTROS DA HISTÓRIA COLONIAL NA LITERATURA DE PAULINA CHIZIANE
}

\author{
Tiago Ribeiro dos Santos ${ }^{*}$ \\ Instituto Federal de Santa Catarina
}

\begin{abstract}
Resumo: $\mathrm{O}$ artigo discute a maneira como a escritora Paulina Chiziane tece seu testemunho acerca do passado colonial de Moçambique nas páginas do romance $O$ alegre canto da perdiz. $\mathrm{Na}$ verdade, a escrita ficcional da autora desestabiliza os discursos em prol da unidade nacional produzidos pela FRELIMO, uma vez que apresenta modos de opressão e de resistência para além daqueles veiculados pela narrativa oficial da Frente de Libertação. Por meio de uma análise centrada em alguns personagens, como Delfina, o artigo propõe uma leitura do romance a partir do corpo como local de trocas e de ambivalências no grande jogo de poder que constituiu a esfera colonial. Assim, o corpo feminino funciona como local de desejo e é o principal produto nas trocas efetuadas no patriarcado, situando-se de forma estratégica na relação entre gênero, poder e maternidade. No romance de Chiziane, os corpos das personagens femininas - e todos os conflitos inerentes a eles - podem ser lidos como metonímia do país, o grande corpo nacional fraturado pelo processo colonizador.
\end{abstract}

Palavras-chave: Testemunho. Paulina Chiziane. Memória.

Beatriz Sarlo, em Tiempo Pasado: cultura de la memoria y giro subjetivo - una discusión (2012) analisa como o testemunho tornou-se uma fonte de verdade sobre o passado a partir do uso da primeira pessoa. Diante disso, é preciso questionar a confiança que a testemunha gera quando decide falar sobre um passado do qual participou. No contexto do colonialismo português em África, a reconstrução do passado é efetuada por meio da memória daqueles que, de alguma forma, participaram da vida no país que sofreu a ação colonial. A partir daí, são construídas narrativas que demonstram o ponto de vista do sujeito invasor ou do sujeito autóctone.

Nessa busca por um "lugar perdido" no passado afloram significados assentados em várias formas de violência. Assim, “o valor de verdade do testemunho pretende sustentar-se

Esta obra está licenciada sob uma Creative Commons - Atribuição 4.0

\footnotetext{
* Doutor em Literaturas pela UFSC e professor de Língua Portuguesa e Literaturas no Instituto Federal de Santa Catarina (IFSC), Câmpus Florianópolis. Seus temas de pesquisa abrangem as Literaturas Africanas de Língua Portuguesa, sobretudo a relação entre mulheres e memórias na obra da escritora moçambicana Paulina Chiziane. E-mail: semh.tiago@gmail.com.
} 
no imediatismo da experiência." (SARLO, 2012, p. 55-56, tradução nossa) ${ }^{1}$. No entanto, a experiência pode configurar uma armadilha, pois $\mathrm{o}$ fato de as testemunhas serem "autorizadas" por meio dela a falar sobre o que vivenciaram não quer dizer que estejam, necessariamente, comprometidas com a verdade.

O discurso ficcional de O Alegre Canto da Perdiz - romance publicado em 2008 pela escritora moçambicana Paulina Chiziane - desmistifica a narrativa fundadora da unidade nacional produzida pelos órgãos de luta contra o colonialismo em Moçambique, como a FRELIMO $^{2}$ e a Organização da Mulher Moçambicana $(\mathrm{OMM})^{3}$, ao tratar as memórias - como faz Elizabeth Jelin (2002, p. 02) - como objetos de disputas e lutas políticas e ideológicas, cujos participantes estão imersos em relações de poder. De acordo com a OMM, "no geral, a mulher não tinha poder de decisão - ela era uma simples executora de tarefas atribuídas pelo homem e pelo regime opressor." (ORGANIZAÇÃO DA MULHER MOÇAMBICANA, 2013, p. 21).

No romance de Paulina Chiziane, comparece um conjunto de memórias testemunhais que vai além da construção de um projeto nacionalista para Moçambique. Nele, há uma luta de mulheres contra o patriarcado e o colonialismo, em que a escrita literária da autora atua no sentido de questionar os discursos oficiais dos agentes que participaram do complexo processo de libertação que se desenrolou no país. O discurso de moçambicanidade da FRELIMO foi instituído por uma narrativa de cariz revolucionário que ocultou as vozes contrárias ao projeto do partido, numa tentativa de identificar com clareza os "inimigos" e puni-los. Essa ocultação deu-se com o uso de violência e repressão severas, uma vez que os "traidores" eram levados aos campos de reeducação, de onde, alguns deles, nunca mais retornaram.

Em Os Condenados da Terra, Frantz Fanon (1968) já alertara para a característica dos partidos nacionalistas de querer ocupar o lugar do colono, inclusive com a utilização de violência contra seus iguais para tomar o poder: "Enquanto o colono ou o policial podem a qualquer momento espancar o colonizado, insultá-lo, fazê-lo ajoelhar-se, vê-se o colonizado

\footnotetext{
${ }^{1}$ De acordo com o texto original: "el valor de verdad del testimonio pretende sostenerse sobre la inmediatez de la experiencia."

${ }^{2}$ Trata-se da Frente de Libertação de Moçambique, partido político fundado em 1962, responsável por liderar a Luta de Libertação no país.

${ }^{3} \mathrm{Em}$ A mulher moçambicana na luta de libertação nacional: memórias do destacamento feminino (2013) - livro coordenado pela historiadora Benigna Zimba e publicado pela Organização da Mulher Moçambicana -, o leitor tem acesso às memórias das mulheres combatentes no processo de luta pela libertação nacional. A partir das várias frentes de luta nas quais atuaram enquanto membros da FRELIMO, as mulheres criaram, em 1973, a Organização da Mulher Moçambicana (OMM), com o objetivo de garantir a sua participação nos processos políticos naquele período em que se desenrolava a luta armada a favor da independência.
}

Anu. Lit., Florianópolis, v. 23, n. 1, p. 99-112, 2018. ISSNe 2175-7917 
sacar a faca ao menor gesto hostil ou agressivo de outro colonizado. (FANON, 1968, p. 40). Nessa passagem, Fanon está se referindo às disputas internas entre os colonizados, como aquelas que iriam resultar nos sangrentos enfrentamentos entre a FRELIMO e a RENAMO ${ }^{4}$ no contexto da guerra civil. ${ }^{5}$

Para entender a relação mantida entre os próprios nativos à época em que começaram a brotar os ideais de libertação, é preciso saber que, durante o colonialismo, muitos deles tornaram-se sipaios e passaram a usufruir de alguns privilégios oferecidos pela administração colonial. Então, quando inicia-se o projeto de libertação liderado pela FRELIMO, essas pessoas - para não perderem os seus privilégios - não aderiram à Frente de Libertação, lutanto ao lado dos portugueses. Em relação a isso, Paulina Chiziane faz uma denúncia a partir da personagem de José dos Montes:

O que José não sabia é que os seus actos se tornariam um marco, história, mito, lenda. Mudariam o mundo. Sem a cumplicidade dos assimilados e seus sipaios a terra jamais seria colonizada. [...] A injúria de branco é estrangeira, passageira. Mas a do teu irmão é espinhosa, o preto José passou para o lado dos brancos. (CHIZIANE, 2008, p. 132-133).

Em O Alegre Canto da Perdiz, a escritora problematiza as relações entre colonizados e colonizadores, quando já eram anunciadas as "fantasias de liberdade" que alimentariam a Guerra de Libertação. No contexto ficcional, ao ser pressionado por Delfina, José dos Montes utiliza a assimilação como estratégia de ascensão social. Diante do oficial de justiça, José faz o juramento de abandonar todas as suas crenças e de não pronunciar nem mais uma palavra na sua língua nativa. É o momento intervalar entre dois mundos: o seu mundo de origem - a que decide renunciar - e o mundo novo, onde se come bacalhau e onde se usam "sabão, perfume e lençóis brancos". (CHIZIANE, 2008, p. 118).

José dos Montes é recrutado para ser sipaio e servir às tropas portugueses. No entanto, ele não entende o significado de "matar ou morrer por uma bandeira" (CHIZIANE, 2008, p. 124). Mesmo considerando-se um homem sem coragem, decide lutar a favor dos portugueses e dar as costas para seu povo. A sua imersão na vida militar lhe possibilita o encontro com os símbolos nacionais, dentre eles, a bandeira, que é vista apenas como um

\footnotetext{
${ }^{4}$ A Resistência Nacional Moçambicana é um partido político de oposição à FRELIMO e foi criada logo após a independência, em 1975.

${ }^{5}$ Frantz Fanon (1968, p. 45-46) alega que, no processo de libertação das colônias, os partidos nacionalistas foram formados a partir de elites coloniais que pretendiam expulsar os colonos para tomar o seu lugar. Na verdade, ao dizer isso, Fanon referia-se aos partidos nacionalistas anteriores às guerras de libertação, que foram responsáveis por tentativas pacíficas de negociação com o colonialismo. No contexto da Guerra de Libertação e da guerra civil enfocadas por Paulina Chiziane, o uso da violência, da guerra, da revolução foi justificado como medida extrema de libertação.
} 
"pedaço de pano" (CHIZIANE, 2008, p. 124). O fragmento abaixo mostra claramente a condição de sujeito sem-lugar a que José dos Montes se expõe:

Era 1953, noite colonial. José dos Montes parte para a guerra. Não como soldado, mas como sipaio. Soldado é coisa de homem, a bravura coisa de marinheiro e ele não passa de um cidadão de segunda. A repressão ganhava novas formas. As gentes andam com fantasias de liberdade e conspiram. Cada negro era um potencial opositor, era preciso aumentar a repressão. (CHIZIANE, 2008, p. 124).

A repressão aludida pela personagem fazia parte de um amplo conjunto de medidas levadas a cabo pela ditadura portuguesa para conter o desejo de libertação que começava a aflorar nas colônias. Nesse momento, muitos nativos foram "condecorados" com a função de sipaio por meio da assimilação. A prerrogativa para assimilar a cultura do opressor era tomar para si as formas de pensamento da burguesia colonial. É o que faz José dos Montes na tentativa de embrenhar-se no mundo do colonizador. No entanto, o personagem assume um locus intermediário próprio da fronteira, num universo cindido em duas partes. Como assinala Franz Fanon (1968, p. 28), a linha divisória, a fronteira, é demarcada pelos quartéis e pelos postos da polícia e é justamente nesses lugares que José atuará na condição de sipaio.

Para acentuar a sua condição de sujeito deslocado entre dois mundos, José dos Montes tem de lidar com a traição de Delfina e, consequentemente, com o nascimento de uma filha mulata. Em certa passagem do romance, o personagem vai à procura de Lavaroupa da Silveira para desabafar sobre o nascimento de sua filha mestiça. Ao receber a visita do sipaio, logo lhe vem à mente que se trataria da cobrança do imposto de palhota ou de alguma questão embaraçosa, como prisão ou qualquer acerto de contas com a polícia, pois na colônia "as pessoas vivem em permanente medo." (CHIZIANE, 2008, p. 193). José dos Montes deslumbra-se com o requinte da casa de Lavaroupa e com a classe de seu amigo, que exibe "anéis de ouro nos dedos de unhas limpas." (CHIZIANE, 2008, p. 195). Mesmo sendo um negro com classe, a personagem carrega um nome de escravo adquirido num interrogatório policial: Lavaroupa de Francisco da Silveira.

Ao ser julgado um escravo insurrecto, ele teria afirmado - para atestar sua inocência - que trabalhava todos os dias lavando a roupa do seu dono, o Senhor Francisco da Silveira. Nas palavras do romance: "Foi em condições semelhantes que nasceram os nomes de muitos zambezianos. Nomes de desencanto e de tudo o que humilha, como as roupas de intimidade e de outras banalidades." (CHIZIANE, 2008, p. 195). De acordo com Lourenço do Rosário, a escolha dos nomes dos colonizados dependia de sua posição, enquanto sujeitos assimilados ou não: 
$\mathrm{Na}$ minha província, por exemplo, as pessoas perderam de tal forma o seu passado que os nomes, até hoje, testemunham este facto. Os assimilados e seus descendentes tomam todos, sobrenomes cristãos e ocidentais, do tipo Costa Xavier, Nobre ou Rodrigues, mas os não assimilados ficaram simplesmente Canivete, Camisa, Cigarro ou Contravento. (ROSÁRIO, 2010, p. 171).

Como demonstra a citação acima, os nomes - ao agregarem significados sociais derivados do processo de colonização - passam a registrar a memória desse processo, contrastando com os valores de matriz religiosa ou cultural próprios das populações africanas. No entanto, como ressalta Cremildo Bahule (2013, p. 83-84), a escolha dos nomes por parte de algumas etnias africanas servia como uma forma de resistência aos valores que eram impostos aos colonizados e - ao conterem elementos relacionados às crenças e tradições das comunidades - eram utilizados de modo a garantir a perpetuação do legado do grupo.

Nesse caso, todos os indivíduos eram submetidos a um rito de iniciação, em que se invocava o nome do totem do qual provinham, para que sua identidade fosse protegida pelos antepassados. Segundo o autor, "a identidade, por meio do nome, é apresentada dentro de uma perspectiva etno-pluralista em que ressalta o carácter particular diferencialista, ou seja, cada grupo deve respeitar a sua imagem, a sua memória, cultivar essa imagem e essa memória para dela se alimentar e ao mesmo tempo alimentar o outro.” (BAHULE, 2013, p. 84).

Além da utilização de nomes por cuja função simbólica se identificava a origem do indivíduo, alguns povos africanos fizeram largo uso de tatuagens para marcar a identidade de um sujeito frente ao processo de escravização. Como várias rotas geográficas foram desenhadas pelo comércio de povos escravizados, as tatuagens cumpriam a função de marcar a linhagem a que o indivíduo pertencia. Assim, onde quer que o sujeito estivesse, ele levaria marcados em seu corpo os símbolos que remeteriam à sua terra.

Nas palavras do romance de Paulina Chiziane, a personagem Maria das Dores - cujo nome "reflecte o cotidiano das mulheres e dos negros" (CHIZIANE, 2008, p. 09) - é encontrada nua pela mulher do régulo às margens do rio Licungo. Ao prestar atenção em Maria, a mulher observa que seu corpo possui tatuagens típicas de habitantes das aldeias. Quando resolve, então, decifrar as mensagens de cada símbolo, conclui que são tatuagens lómwè, um povo habitante das montanhas. De acordo com a autora,

os povos africanos tiveram de carimbar os corpos com marcas de identidade. Cada tatuagem é única. É marca de nascença. No corpo, desenhando-se o mapa da terra. Da aldeia. Da linhagem. Em cada traço uma mensagem. Árvore genealógica. A tatuagem ajudou à reunificação dos membros da família, em São Tomé. Na América. Nas Caraíbas. Nas Ilhas Comores, em Madagáscar, nas Maurícias e outros lugares do mundo. Mudaram-se os tempos, os africanos não precisam mais de tatuagens, terminou o tempo da escravatura. (CHIZIANE, 2008, p. 31). 
Com o fim da escravização, os corpos femininos - como o de Maria das Dores deixarão de ser carimbados com tatuagens, no entanto, não ficarão incólumes diante do desejo de dominação masculina. No contexto do colonialismo, os corpos - sobretudo os corpos das mulheres - circulam por lugares fixos e ermos e são postos à deriva, de onde só são resgatados para servir aos interesses da máquina colonial. As "rotas" previstas para a circulação desses corpos podem ser localizadas nas memórias que identificam "como o 'corpo' foi produzido como um lugar onde a dominação se exercia, e onde se construía o poder, em termos de gênero e raça. Por outro lado, o corpo foi, também, lugar de resistência e de memória." (SCHMIDT, 2014, p. 229) .

$\mathrm{Na}$ ótica do romance de Paulina Chiziane, o corpo é quase uma personagem sobretudo o corpo da protagonista Delfina -, pois é o mecanismo que lhe possibilita transitar entre os mundos do colonizado e do colonizador. Ela deseja, ilusoriamente, ocupar o lugar da mulher branca do português Soares, homem com quem gera Jacinta, sua filha mulata. A ilusão de Delfina a acompanha durante todo o romance e o leitor fica a saber de seus desejos motivados pela inveja - pois, como mostra Fanon (1968, p. 39), “o colonizado é um invejoso" diante do exibicionismo do colonizador. Ao caminhar pelas ruas da cidade logo após encontrar-se com o curandeiro Moyo - que lhe faz várias previsões -, Delfina inveja a vida que os brancos levam. Ela encanta-se com a eletricidade, com a iluminação das casas, com os prédios e hotéis espalhados pela cidade. Conforme as palavras do romance,

\footnotetext{
o coração de Delfina constrói cidades de neón. Com muita comida e muito vinho. No seu sonho é senhora e habita uma cidade de pedra. Com vestidos de renda. Criados tão pretos como ela que tratará como escravos. Um marido branco e filhas mulatas a quem irá pentear os cabelos lisos e amarrar com fitinhas de seda. Terá a grandeza das sinhás e das donas, apesar de ser negra, ela sente. Receberá favores do regime. As mulheres negras que casam com brancos sobem na vida. Comem bacalhau e azeitonas, tomam chá com açúcar, comem pão com manteiga e marmelada. (CHIZIANE, 2008, p. 77-78).
}

Para concretizar seu plano, Delfina utiliza-se da única arma que possui: seu corpo. Por isso, ela usa todas as artimanhas para seduzir os marinheiros do cais. Na família da protagonista, podemos observar uma "cultura" do uso do corpo das mulheres como mercadoria de troca. Nesse contexto, as mulheres da família são submetidas a trocas que lhes garantem recompensas materiais. Como observa Simone Schmidt (2014, p. 231), há no romance a descrição de uma "genealogia da subalternidade feminina", uma vez que Delfina vende a virgindade de sua filha Maria das Dores ao curandeiro Simba, do mesmo modo que sua mãe vendeu sua virgindade. Ao final do romance, quando encontra-se sozinha, a

\footnotetext{
${ }^{6}$ Grifo da autora.
} 
protagonista "reúne as últimas forças e ergue e realiza um sonho antigo: abrir um prostíbulo para fornecer raparigas virgens por encomenda." (CHIZIANE, 2008, p. 269).

Ao retirar de Delfina a imagem da mãe que acolhe todos os filhos com igualdade, Paulina Chiziane põe em jogo os usos estratégicos relacionados às noções de corpo, gênero e maternidade elaborados pela protagonista. Podemos observar que Delfina utiliza-se das estratégias de gênero que the são permitidas no âmbito do colonialismo para alcançar uma posição negada aos de sua raça. Assim, a sua condição de negra assimilada e o uso "estratégico" - leia-se sexualizado - de seu corpo lhe rendem favores no ambiente hostil do colonialismo.

A estrutura responsável por transformar a sexualidade biológica em um produto social - denominada por Gayle Rubin $(1993)^{7}$ como "sistema sexo/gênero" - é utilizada, aqui, para analisar as trocas sexuais efetuadas no romance de Paulina Chiziane. Nesse sistema, as "fềmeas" - termo utilizado para enfatizar o dado biológico do sexo - são transformadas em mulheres domesticadas. Para Rubin, resta saber o modo como esse aparato social, no seu processo de domesticação das mulheres, acaba por oprimi-las. Em sua leitura de O Capital, de Marx, a autora se dá conta de que ele entende o processo de escravização dos negros a partir das relações sociais estabelecidas, pois um negro é, antes de tudo, um negro; e só se torna escravo por meio das opressões raciais construídas socialmente. É aí que Rubin, ao parafrasear Marx, lança sua pergunta:

O que é uma mulher domesticada? Uma fêmea da espécie. Uma explicação é tão boa quanto a outra: uma mulher é uma mulher. Ela só se torna uma doméstica, uma esposa, uma mercadoria, uma coelhinha, uma prostituta ou ditafone humano em certas relações. Retirada dessas relações, ela não é mais companheira do homem do que o ouro, em si mesmo, é dinheiro... etc. (RUBIN, 1993, p. 02).

As respostas que a autora mesma tece para sua pergunta demonstram que a sociedade pensa - e constrói - a diferença sexual a partir da subordinação das mulheres. Para encontrar vestígios da origem dessa opressão, Gayle Rubin procura pistas em Freud, Lévi-Strauss e Marx - embora reconheça que esse último não estivesse interessado na diferença sexual quando propôs sua teoria da vida social. De acordo com a análise da autora acerca do Capitalismo - do modo como foi estudado por Marx -, não podemos afirmar que esse sistema foi responsável pela opressão das mulheres, uma vez que as práticas opressivas em relação a

\footnotetext{
${ }^{7}$ Trata-se do texto "O tráfico de mulheres: notas sobre a economia política do sexo", publicado originalmente em 1975. Em entrevista concedida a Judith Butler (RUBIN; BUTLER, 2003, p. 160), a autora afirma o seguinte: "O que inspirou meu artigo 'Traffic' foi um curso sobre economia tribal dado por Marshall Sahlins na Universidade de Michigan, por volta de 1970. Aquele curso mudou minha vida. Eu já mantivera contato com feministas, mas aquela foi minha primeira experiência com antropologia, e eu fiquei apaixonada. Fiquei encantada com a abordagem teórica de Sahlins, e também com a riqueza descritiva da literatura etnográfica."
} 
elas apenas passaram a ter novos formatos.

Além disso, verificamos práticas opressivas em sociedades não capitalistas. ${ }^{8}$ Isso, no entanto, não nos impossibilita de pensar nas maneiras como o Capitalismo utilizou - e reciclou - as formas de opressão das mulheres para garantir a mais-valia. Sobre isso, Maria Paula Meneses salienta que "a rígida separação dos papéis de género que se tornou uma característica da modernidade europeia não estava presente na maioria do continente na época pré-colonial. Isto não significa que a separação de género não existisse; existiam divisões, porém, as suas fronteiras eram fluidas.” (MENESES, 2008, p. 74).

Ao investigar o livro de Lévi-Strauss, As Estruturas Elementares do Parentesco, Rubin entende que se trata de um trabalho em que seu autor, ao traçar diversas formas de conjugalidade existentes nas sociedades estudadas, importa-se com a sexualidade, ou seja, estabelece uma distinção entre a atuação de homens e mulheres: "no momento em que LéviStrauss vê a essência do sistema de parentesco consistindo na troca das mulheres entre homens, ele constrói uma implícita teoria da opressão sexual”. (RUBIN, 1993, p. 07). Dentre todos os elementos envolvidos nas formas de parentesco estudados por Lévi-Strauss, dois deles têm a ver diretamente com o modo pelo qual as mulheres se relacionam com os homens: a dádiva e o tabu do incesto.

A dádiva, como propõe o estudo no qual Lévi-Strauss se baseia - o Ensaio sobre a dádiva, de Marcel Mauss (1974) -, é a troca de presentes efetuadas desde as sociedades primitivas. A doação de presentes enseja um momento de união de grupos e fortalece seus laços de solidariedade. Sela-se, então, um vínculo social a partir da entrega recíproca de presentes nessas sociedades. Mauss acredita que a troca de presentes era uma espécie de contrato primitivo para legitimar a paz, cuja função foi substituída, atualmente, pelo poder do Estado.

Lévi-Strauss apropria-se do Ensaio sobre a dádiva, de Mauss, para ir mais longe: segundo ele, os casamentos funcionam como verdadeiras trocas de presentes, onde as mulheres são os mais valiosos objetos de troca entre os homens. Nesse mecanismo, o tabu do incesto funciona como uma ferramenta para assegurar que as trocas ocorram entre grupos distintos, logo, que as mulheres sejam trocadas com homens de outros grupos. Apesar de muitos explicarem que a função do tabu do incesto é proibir uniões entre parentes próximos, Lévi-Srauss refuta essa tese por causa da variedade de proibições que se efetuam nos

\footnotetext{
${ }^{8}$ De acordo com Rubin (1993, p. 04), "as mulheres são oprimidas em sociedades que, por maior que seja o esforço de imaginação, não podem ser descritas como capitalistas. No vale do Amazonas e nos altiplanos da Nova Guiné, as mulheres são frequentemente mantidas nos seus lugares por meio de estupro coletivo, quando os mecanismos ordinários de intimidação masculina se demonstram insuficientes".
} 
diferentes grupos humanos. Assim, o tabu do incesto é universal, no entanto, as proibições se diferem em cada sociedade.

As relações de parentesco nascem, segundo Lévi-Strauss, a partir da troca de mulheres. Na dádiva, assim como há a troca de produtos agrícolas, gado, feitiços, palavras, conchas e outros elementos, há também a troca de mulheres. Nesse caso, elas constituem os presentes que se trocam entre ofertantes homens e, por isso, não têm benefício algum. Apesar de longa, a citação a seguir define claramente a percepção da autora quanto às trocas, pois, para ela,

a "troca de mulheres" é um conceito sedutor e poderoso. É atrativo, na medida em que ele coloca a opressão das mulheres dentro de sistemas sociais, em lugar da biologia. Além disso, ele nos sugere procurar o último locus da opressão das mulheres no tráfico destas, em lugar do tráfico de mercadorias. Certamente não é difícil encontrar exemplos etnográficos e históricos do tráfico de mulheres. As mulheres são dadas em casamento, ganhas nas batalhas, trocadas por favores, enviadas como tributo, comercializadas, compradas e vendidas. Longe de serem confinadas ao mundo "primitivo", estas práticas parecem apenas tornar-se mais afirmadas e comercializadas nas sociedades mais "civilizadas". Naturalmente, homens são também traficados - mas como escravos, prostitutos, estrelas do atletismo, servos ou com qualquer outro estatuto social catastrófico, antes que como homens. E se os homens têm sido sujeitos sexuais - trocadores - e as mulheres semi-objetos-sexuais - presentes - durante a maior parte da história humana, então muitos costumes, clichês e traços de personalidade parecem ter muito sentido (entre outros, o curioso costume pelo qual o pai entrega a noiva). (RUBIN, 1993, p. 10).

O trecho acima demonstra como Rubin, ao analisar as "trocas" sexuais do patriarcado - a partir de Lévi-Strauss -, desenvolve um pensamento inédito e fundador para os estudos feministas, pois faz nascer uma importante reflexão em torno do que denomina "sistema sexo-gênero". Todavia, quando o antropólogo afirma que o tabu do incesto está na origem da cultura - e como o sistema de parentesco que é fundado por esse tabu é baseado na troca de mulheres -, ele consequentemente quer dizer que a opressão das mulheres constitui parte integrante do momento de fundação da cultura. Isso é questionado ironicamente pela autora, pois, como se não bastasse ter de eliminar os homens para pôr fim à opressão das mulheres, seria preciso também eliminar toda a cultura criada até hoje na face da terra.

Pensar sobre o uso dos corpos no contexto do colonialismo é tentar entender o modo como se processaram as relações sociais mediadas pelo seu uso. Assim, o maniqueísmo instaurado pelo discurso colonial, principalmente a partir da noção de raça, sempre foi utilizado para marcar a diferença entre corpos negros e brancos. Como assinala Rita Segato, o “engessamento de posições identitárias é também uma das características da racialização, instalada pelo processo colonial moderno, que impele os sujeitos para posições fixas dentro do cânone binário aqui constituído pelos termos branco - não branco.” (SEGATO, 2012, p. 
126).

A partir da afirmação acima, notamos como a raça é um mecanismo intermitente que sempre convoca os sujeitos para ocuparem lugares fixos, que são estrategicamente demarcados. No romance, a condição de assimilados de Delfina e José dos Montes eleva-os socialmente, porém, a cidadãos de segunda classe. E o fato de Soares voltar para os braços de sua mulher branca, em Portugal, e abandonar Delfina, configura um uso esporádico do seu corpo negro, "prática muito comum na relação entre portugueses e mulheres africanas no período colonial", como aponta Simone Schmidt (2014, p. 237).

No âmbito do feminismo, Adrienne Rich $(2002)^{9}$ aposta na materialidade do corpo e na geografia como uma saída estratégica para analisar as relações de poder de modo localizado. Tal como Rich - para quem o corpo é algo passível de abstração, construído e significado pela sociedade -, Stuart Hall (2000, p. 121) crê que "o corpo é construído, moldado e remoldado pela intersecção de uma variedade de práticas discursivas disciplinares". Ao utilizar metáforas da topografia e da geografia para se pensar a linguagem cartográfica das fronteiras, a autora propõe um estudo a partir da materialidade do corpo feminino: "Começar, assim, não por um continente, por um país ou por uma casa, mas pela geografia mais próxima - o corpo.” (RICH, 2002, p. 17).

Pensando a partir da materialidade corporal, como pondera Adrienne Rich, percebemos que a personagem Delfina - ao utilizar seu corpo como via de sustento e de erotismo para atrair homens brancos - faz dele uma intensa zona de contato $^{10}$, no sentido expresso por Mary Pratt (1999). Com esse conceito, a pesquisadora alude às zonas de intersecção onde se refazem constantemente as identidades e se negociam as diferenças. Ao falar em zona de contato, a teórica canadense propõe "uma ótica que tira a comunidade (e a identidade, seu corolário) do centro para examinar a maneira como os laços sociais vão se fazendo por entre linhas de diferença, de hierarquia e de pressupostos conflituosos ou não compartilhados." (PRATT, 1999, p. 12).

Tomando o corpo da protagonista como um local ambíguo - onde se juntam os conflitos na esfera do colonialismo e, ao mesmo tempo, de onde eles partem -, notamos que ele exerce a função de uma verdadeira "zona de contato" intermediada por relações de várias ordens, como a segregação racial, a mestiçagem e os conflitos étnicos. Na verdade, essa ideia do corpo como palco da zona de contato apresenta contornos mais nítidos ao analisarmos o corpo mestiço de Jacinta, a filha mulata de Delfina, que vive sem lugar numa "casa de todas

\footnotetext{
9 Trata-se de um texto clássico no âmbito dos estudos feministas, publicado originalmente em 1984.

${ }^{10}$ Cf. PRATT, 1999.
} 
as raças". De acordo com as palavras do romance:

Um dilema que crescia na sua cabecinha: afinal de contas qual é o meu lugar? Porque é que tenho que me ficar entre as duas raças? Será que tenho que criar um mundo meu, diferente, marginal, só com indivíduos da minha raça? Começou a desenvolver uma raiva contra o pai. Que amou uma preta para transformá-la em mulata. Sentia uma raiva contra a mãe. Que não a fez preta como Maria das Dores e por isso não podia entrar na dança de roda nas esquinas do bairro. [...] Era estranho viver numa casa de todas as raças. (CHIZIANE, 2008, p. 247-248).

Stuart Hall (2000) aborda as formas de poder entremeadas nas práticas sociais e perpassadas por noções como a de raça, que não tem validade científica. No caso da identidade de Jacinta, há que se levar em conta que ela, além de escamotear diferenças étnicas e sociais, contém significados para formas de exclusão situadas historicamente. Na verdade, a raça é uma categoria discursiva que se presta aos jogos de poder da sociedade, pois, mesmo que essa noção não possa ser apreendida a partir da língua ou de características fenotípicas próprias, ela serve como uma estratégia de marcação da diferença social.

Além de serem constituídas pelo discurso, pelos jogos de poder e por estratégias específicas, as identidades, antes de se constituírem como unidades, são formas de marcação da diferença e da exclusão. Assim, Jacinta sente "na pele" a marcação dessa diferença quando sofre os preconceitos na escola ou quando tem dificuldades de acessar alguns lugares, como as danças de roda no seu bairro. Sua identidade fraturada pela condição de mestiça tem origem em um passado colonial que continua a deixar marcas de exclusão nos sujeitos mesmo após a independência.

Ao final do romance $O$ Alegre Canto da Perdiz, todas as imagens do tempo colonial comparecem nas memórias de Delfina: desde a pompa dos casarões até as mais terríveis formas de violência experimentadas durante o regime. A narrativa deságua, então, na independência de Moçambique, quando os membros dispersos da família novamente se reúnem: "A morte e o luto desocuparam a terra, no ar governam os alegres cantos das perdizes, gurué, gurué! A escravatura acabou e não voltará nunca mais! Somos independentes. Vencemos o colonialismo." (CHIZIANE, 2008, p. 331).

Desenha-se, nesse momento da narrativa, um projeto de nação para Moçambique. Ao longo de todo o romance, testemunha-se a projeção de um corpo nacional, que só é efetivamente criado com a saída dos portugueses. No entanto, o texto literário da autora "confronta, indubitavelmente, o esquecimento da colonialidade, retirando essa memória da sombra da História ao colocar a modernidade par a par com a sua própria ambiguidade, dualidade e miséria." (KHAN, 2014, p. 214). Como assinala Sheila Khan, a colonialidade 
deixará suas marcas no corpo das personagens - sobretudo nos corpos femininos - e em suas memórias, pois "o colonialismo é macho, engravidou o ventre de tua mulher. Roubou o beijo da tua namorada e o sorriso dos teus filhos." (CHIZIANE, 2008, p. 132).

A figura do colonizador, aqui, tem a ver com a imagem do pai na psicanálise - o sujeito masculino opressor -, responsável por realizar as trocas que alimentam o patriarcado. Assim, quando Paulina Chiziane descreve o colonialismo como "macho", ela salienta o caráter invasor da colonização e faz com que sua narrativa opere, ficcionalmente, a partir do mecanismo de controle dos corpos e dos sujeitos implementado pelo colonialismo. Como assinala Maria Paula Meneses (2008, p. 78), nos lugares onde originalmente predominava a cultura matrilinear - como o Norte de Moçambique -, as mulheres foram perdendo o poder diante dos homens, uma vez que a administração colonial fez alianças com chefes locais, reduzindo, assim, a visibilidade que mantinham na esfera pública.

Além de podermos situar Moçambique como um grande corpo invadido, nossa leitura calcada no gênero permite vislumbrar os corpos femininos como verdadeiros testemunhos da mercantilização, assimilação e mestiçagem que se processam no romance. Todos esses mecanismos só são possíveis graças à utilização do corpo como lugar privilegiado para promover a histórica opressão das mulheres, que são "traficadas" por homens e utilizadas como moedas de troca no âmbito do "sistema de sexo e gênero" amplamente praticado no sistema colonial.

\section{Referências}

BAHULE, Cremildo. Literatura feminina, Literatura de purificação: o processo de ascese da mulher na trilogia de Paulina Chiziane. Maputo: Ndjira, 2013.

CHIZIANE, Paulina. O Alegre Canto da Perdiz. Lisboa: Editorial Caminho, 2008.

FANON, Frantz. Os Condenados da Terra. Trad. de José Laurênio de Melo. Rio de Janeiro: Civilização Brasileira, 1968.

HALL, Stuart. Quem precisa da identidade? In: SILVA, Tomas Tadeu (Org.). Identidade e diferença: a perspectiva dos Estudos Culturais. Petrópolis: Vozes, 2000, p. 103-133.

JELIN, Elizabeth. Los trabajos de la memoria. Madrid; Buenos Aires: Siglo Veintiuno de España; Siglo Veintiuno de Argentina Editores, 2002.

KHAN, Sheila. Pedir licença na terra que é nossa: a miséria da colonialidade em $O$ Alegre Canto da Perdiz. In: MIRANDA, Maria Geralda de; SECCO, Carmem Lúcia Tindó Ribeiro. Paulina Chiziane: Vozes e rostos femininos de Moçambique. Curitiba: Appris, 2014, p. 203216. 
MAUSS, M. Ensaio sobre a dádiva: Forma e razão da troca nas sociedades arcaicas. In: . Sociologia e Antropologia. v. II. São Paulo: Edusp, 1974.

MENESES, Maria Paula. Mulheres insubmissas? Mudanças e conflitos no Norte de Moçambique. Ex aequo, Lisboa, n. 17, p. 71-87, 2008.

ORGANIZAÇÃO DA MULHER MOÇAMBICANA (Moçambique). A mulher moçambicana na luta de libertação nacional: memórias do destacamento feminino. Maputo: Movimento Editora, 2013.

PRATT, Mary Louise. A crítica na zona de contato: nação e comunidade fora de foco. Travessia, Florianópolis, n. 38, p. 07-29, Jan./Jul. 1999.

RICH, Adrienne. Notas para uma política da localização (1984). In: MACEDO, Ana Gabriela (org.). Gênero, desejo e identidade. Lisboa: Cotovia, 2002, p. 15-35.

ROSÁRIO, Lourenço do. Moçambique: história, culturas, sociedade e literatura. Belo Horizonte: Nandyala, 2010.

RUBIN, Gayle. O tráfico de mulheres: notas sobre a economia política do sexo. Trad. de Christine Rufino Dabat, Edileusa Oliveira da Rocha e Sonia Corrêa. Recife: SOS Corpo, 1993. 157-209, $2003 . \quad$ Disponível http://www.scielo.br/scielo.php?script=sci_arttext\&pid=S0104-
$83332003000200008 \& \operatorname{lng}=\mathrm{en} \& \mathrm{nrm}=$ iso. Acesso em: 30/01/2018.

SARLO, Beatriz. Tiempo pasado: cultura de la memoria y giro subjetivo. Una discusión. Buenos Aires: Siglo Veintiuno Editores, 2012.

SCHMIDT, Simone P. Corpo e terra em O Alegre Canto da Perdiz. In: MIRANDA, Maria Geralda de; SECCO, Carmem Lúcia Tindó Ribeiro. Paulina Chiziane: Vozes e rostos femininos de Moçambique. Curitiba: Appris, 2014, p. 229-247.

SEGATO, Rita Laura. Gênero e colonialidade: em busca de chaves de leitura e de um vocabulário estratégico descolonial. E-cadernos CES, n. 18, p. 106-131, 2012.

\section{Traces of colonial history in Paulina Chiziane's literature}

Abstract: The article discusses the way the writer Paulina Chiziane weaves her testimony about the colonial past of Mozambique in the pages of the novel $O$ alegre canto da perdiz. In fact, the author's fictional writing destabilizes the discourses for the national unity produced by FRELIMO, since it presents modes of oppression and resistance beyond those conveyed by the official narrative of the Liberation Front. Through an analysis focused on some characters, such as Delfina, the article proposes a reading of the novel from the body as a place of exchanges and ambivalences in the great power game that constituted the colonial sphere. Thus, the female body functions as a place of desire and is the main product in the exchanges effected in the patriarchy, strategically located in the relation between gender, power and motherhood.

Keywords: Testimony. Paulina Chiziane. Memory. 
Recebido em: 09/02/2018

Aceito em: 15/02/2018

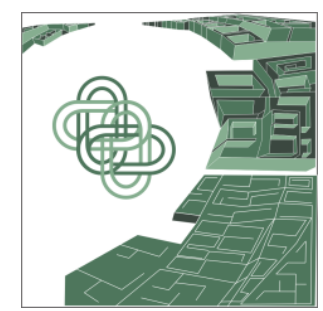

